\title{
Effects of Different Soil Water Potential at Tillering Stage on Rice Yield and Physiological Traits in Saline-alkali Soil
}

\author{
Jin Feng ${ }^{1, a}$, Geng Yan-qiü2.b, Hua Shuang ${ }^{3, c,}$ Huang xiao-xuan ${ }^{4, d, ~ L i u ~}$ \\ yue-yue ${ }^{5, e}$, Shao Xi-wen $6, f$ \\ 1 JiLin Agricultural University, Changchun 130118 \\ 2 JiLin Agricultural University, Changchun 130118 \\ 3 JiLin Agricultural University, Changchun 130118 \\ 4 JiLin Agricultural University, Changchun 130118 \\ 5 JiLin Agricultural University, Changchun 130118 \\ 6 JiLin Agricultural University, Changchun 130118 \\ a jinfeng911@126.com, b59564825@qq.com, c 451533993@qq.com, d 1184773883@qq.com, e \\ 2453209887@qq.com, f 542389720@qq.com (Corresponding author)
}

Key word: rice, tillering stage, saline-alkali soil, water stress, physiological traits, yield

Abstract: To explore the effects of different soil water potential of tillering stage on rice yield and physiological traits in saline-alkali soil, using four treatment levels of soil water potential of $0 \mathrm{kPa}$ (H1: soil moisture), soil water potential of $-15 \mathrm{kPa}(\mathrm{H} 2)$, soil water potential of $-30 \mathrm{kPa}(\mathrm{H} 3)$, and CK (continuously flooded), a comparative study of different soil water potential of tillering stage on grain yield, dry matter production, leaf physiological treats and growth dynamic was conducted. The results showed that the period of water stress, the leaf relative water content of the soda saline soil of rice had declined rapidly, and the falling range with the same level of water stress. The H1 had recovering the level of $\mathrm{CK}$ after 15days of rewatering. The tiller number from high to low showed a trend of $\mathrm{CK}>\mathrm{H} 1>\mathrm{H} 2>\mathrm{H} 3$ with the drop of water potential in saline-alkali soil, the date of top tillering was the same from $\mathrm{CK}$ to $\mathrm{H} 1$, but $\mathrm{H} 2$ and $\mathrm{H} 3$ had 5-10 days later than $\mathrm{CK}$. Water stress could restricted the expansion of the rice leaf area and with the exacerbation of the water stress degree, the rice leaf area index decreased. The date ofH1, $\mathrm{H} 2$ and $\mathrm{H} 3$ come to maximum LAI were delayed 5days compared with $\mathrm{CK}$. There had a significantly different among all treatments as to the dry matter accumulation, showed a trend of $\mathrm{H} 1>\mathrm{CK}>\mathrm{H} 2>\mathrm{H} 3$, and the difference between $\mathrm{H} 1, \mathrm{CK}$ and $\mathrm{H} 2, \mathrm{H} 3$ had reached significant level $(\mathrm{P}<0.05)$. The rice yield from high to low showed a trend of $\mathrm{CK}>\mathrm{H} 1>\mathrm{H} 2>\mathrm{H} 3$, compared with the $\mathrm{CK}$, the $\mathrm{H} 1 \backslash \mathrm{H} 2$ and $\mathrm{H} 3$ decreased $11.45 \%$, $24.92 \%$ and $60.24 \%$ respectively in the soda saline- alkali soil under moist irrigation at the tillering stage. So in soda saline-alkali soil continuously flooded irrigation is necessary.

\section{Introduction}

The Songnen Plain is the largest plain in northeast China and the second largest plain of China after the Huang-Huai-Hai Plain in central China. The west side of this plain, mainly the western portion of Jilin and Heilongjian Provinces, is one of the five largest salt affected soil regions in 
China $^{[1] .}$ The area of salt affected soil, 0.5 to $1.0 \%$ total salts, encompasses $3.42 \times 106$ ha, which accounts for over $19.0 \%$ of the total area ${ }^{[1,2]}$. In order to effectively utilize these saline-sodic soils, rice (Oriza sativa $L$.) was planted in this plain because the flooded water not only is beneficial to its growth but also is necessary for leaching salts. In recent years, with the shortage of water resources, the contradiction between the development of rice and the limited water resources was sparked, so more and more people pay more attention to problem of the paddy field water saving. There had lots of reports about water-saving rice, regulation of irrigation and water and soil coupling et al. at present. The results showed that Irrigation water as long as mete the physiological water requirement and ecological water requirement, the higher yield could been gained and the more irrigation water was wasted ${ }^{[2-5]}$. The moderate drought stress could helped build suitable plant type structure, rise net photosynthetic rate and vigor of leaf ${ }^{[6-9]}$. The interval irrigation could to be benefit of good quality high yield. The research of effects of different degree water stress at different growth and development stage was the theoretical basis of water-saving irrigation for rice ${ }^{[1,10-14]}$. For the sake of rice in different growing phases have different demand for water, the reaction of after suffer a certain degree of water stress was not the same, and in a certain growing stage showed a strong patience, while in some stage reaction was very sensitive ${ }^{[12-17]}$. So far the planting structure for water-saving on soda saline-alkali soil, especially investigation of plant growth dynamic and dry matter distribution mechanism at the tillering stage of rice were very little. We therefore conducted a study to determine how effective different water potential is at plant physiological characteristics, dry matter accumulation and yield of rice, discuss the soil moisture adaptability of rice tillering stage in these saline-sodic soils in the western part of Songnen Plain. These results could provide a scientific basis for sustainable development and water-saving drought-resistant cultivation in saline-sodic soils.

\section{Materials and method}

Materials and experimental site

This test was conducted at test base of Jilin Agricultural University in 2013-2014. The variety of changbai 9 with its main varieties of soda soline-alkali soil was used to studied. The average values of $\mathrm{pH}$, salinity, organic content, available $\mathrm{N}$, available $\mathrm{P}$ and available $\mathrm{K}$ for the selected soil were $8.52,0.23 \%, 1.89 \%, 158.8 \mathrm{mg} / \mathrm{kg} 、 32.64 \mathrm{mg} / \mathrm{kg}$ and $153.6 \mathrm{mg} / \mathrm{kg}$ respectively.

Experimental design

We used pot methods in the early stage of the rice tillering by manual control water processing. We measured leaf physiological traits, dry matter production and yield under soil water potentials of $0 \mathrm{Kpa}(\mathrm{H} 1),-15 \mathrm{Kpa}(\mathrm{H} 2),-30 \mathrm{Kpa}(\mathrm{H} 3)$ and $\mathrm{CK}$ (continuously flooded).

Management method

Planted seedling pots with floor diameter $20 \mathrm{~cm}$, upper diameter of $31 \mathrm{~cm}, 33 \mathrm{~cm}$ deep were installed $15 \mathrm{~kg}$ per pot dry soil. The base fertilizer were used a compound fertilizer with include $15 \% \mathrm{~N}, 15 \% \mathrm{P}_{2} \mathrm{O}_{5}$, and $15 \% \mathrm{~K}_{2} \mathrm{O}$ with per pot used $8.0 \mathrm{~g}$. The topdressing times on June 9, July 10 using urea $1.0 \mathrm{~g}$ per pot respectively. Forty-five day old seedlings were transplanted on May 24, into columns. Four seedings per hill, four hills per pot were transplanted into each pot. Water treatment was conducted on June 10, and rewatering on June 25, a total 15days water controlled in two years for the sake of reproductive process of two years were consistently. Rainproof with opened on sunny days, clouded on rainy days or at evening, was installed during test to prevented natural precipitation that guaranteed other ecological factors close to the natural environment under condition of artificial controlled water. 
Sampled and measured

Leaf relative water content (RWC). Each treatments were pick 6flag leaf and packing by vacuum membrane. After weighing take these leaves to a vessel with containing distilled water and absorbing water saturated state, and in the $24 \mathrm{~h}$ later weighing again. $\mathrm{RWC}(\%)=[$ (fresh weight-dry weight $) /($ water saturated state weight-dry weight $)] \times 100 \%$

Tiller number and LAI. Since June 10, we was measured the tiller number of 3 plot each treatment for every 5 days and measure all green leaf length (midrib long) and width (maximum width) . LAI $=[\operatorname{Long}(\mathrm{cm}) \times$ width $(\mathrm{cm}) \times 0.75] /$ area(land)

Dry matter. All the plants of two pots were picked for measure dry mater on june 24(the day of over water treatment), July 10(15 days after rewatering), July 25(jointing-booting stage), August 10(heading stage), August 25(filling stage) and September 10(dough stage). The ground part of plant was separated by stem and sheath, leaf and spike. Beginning in $105{ }^{\circ} \mathrm{C}$ oven for $30 \mathrm{~min}$, and then under the $80{ }^{\circ} \mathrm{C}$ drying to constant weight, weigh the dry weight of after cooling to room temperature.

Yield. The mature crop was harvested by cutting it at soil level. After sun-drying, the heads were counted and separated from the straw to record the number of heads and the weight of straw. Threshing was done by hand and grain number was recorded. Data was calculated panicle number, grains per panicle, 1000-grain weight, seed setting percentage and Yield.

Statistical data analysis

All data obtained were the average of three replicas. Statistical analysis on one-way variance analysis (ANOVA) was performed using SPSS 17.0. When significance at a 0.05 level was indicated, means were separated by a Least Significant Difference (LSD) Procedure.

\section{Result and discussion}

Leaf relative water content

The Leaf relative water content of rice growth in soda saline-alkali soils declined rapidly during water stress(Fig.1), and the falling range consistent with the degree of stress. RWC of H1 suffered water stress after 15 days was $7.78 \%$, which lower than that of $\mathrm{CK}$. When rewatering 15 days, the RWC could recovered to the level of CK. The RWC of H2 and H3 were lower than CK by $12.29 \%$ and $14.42 \%$, respectively, and could rapidly been promoted, there could to flat the level of CK at heading stage. Above results indicated that there had correlation between leaf relative water content of rice and water potential in soda saline-alkali soils.

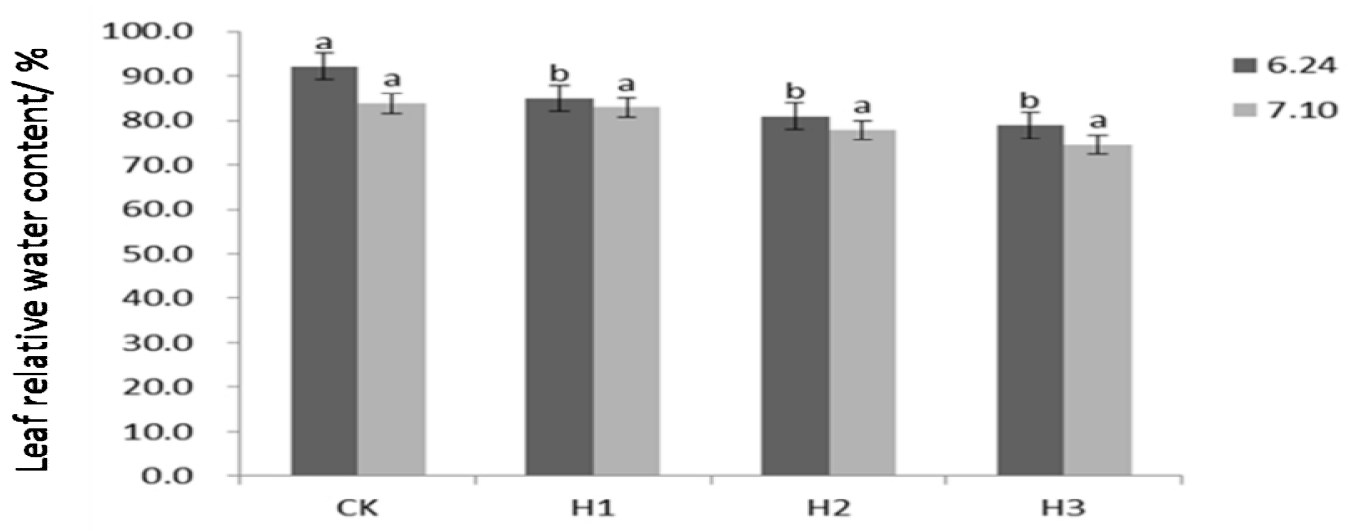

Fig.1 Effects of different soil water potential on relative water content of rice leaves

Dynamics of tiller number

Different water controlled treatment of rice on soda saline-alkali soils, has had greater effects 
on tiller number. After water stress treatment, the tiller number of $\mathrm{CK}$ with 20.45 was the highest $\mathrm{H} 1$ was18.22, H2 was17.01 and H3 had the least tiller number with only 14.64.The same date of top tillering stage between CK and H1, which on July 15, had achieved the maximum tiller number. The tiller could been growth rapidly after rewatering, and the date of maximum tiller number were later 5 to10days than CK. With the development of rice, the tillers of growth later, had most become invalid tillers for light, nutrition and other reasons and the valid tiller rate was at a lower level eventually. From the tiller dynamic curve we known that the inhibitory effect of mild water stress on rice tillering stage in soda saline-alkali soils is not obvious, but could been effectively decreased the invalid tillers, while severe water stress could significantly inhibit the occurrence of rice tillers, and ultimately affect the effective panicle number of rice.

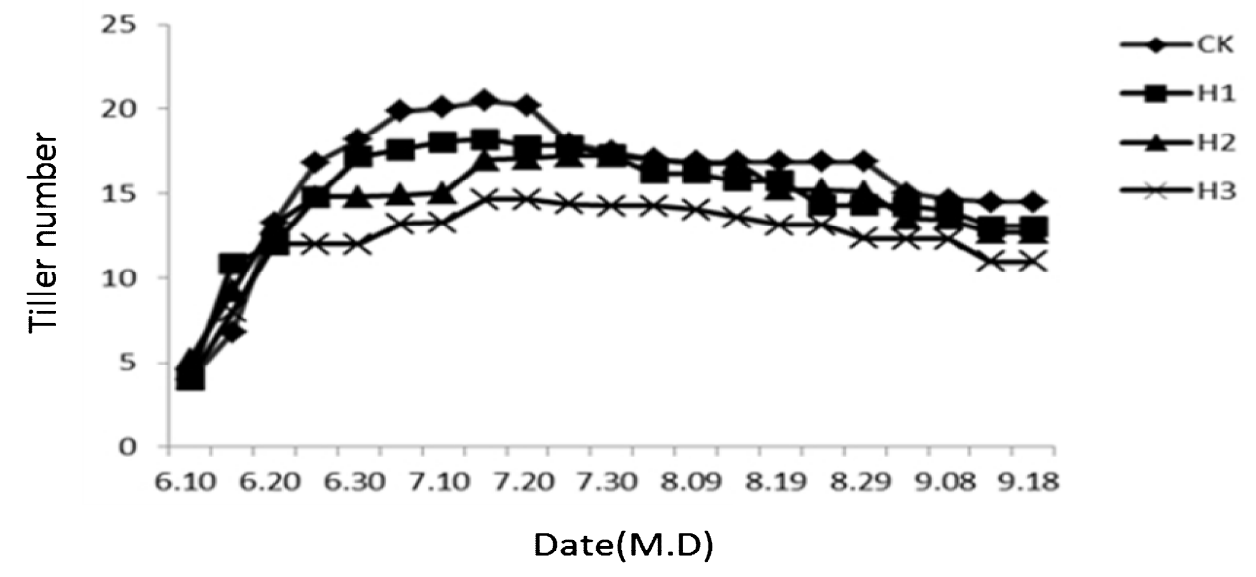

Fig.2 Effects of different soil water potential on tillering dynamics of rice

LAI of rice

Leaf area was the basis of photosynthesis and the main characteristics of the source, appropriate leaf area index was very important to yield formation. From the fig. 3 showed that water stress at tillering stage would restricted the expansion of the rice leaf area, with the aggravation of the water stress level, leaf area index had decreased. The LAI showed a trend of CK $>\mathrm{H} 1>\mathrm{H} 2>\mathrm{H} 3$, with from the largest to least were 5.45,5.30,4.36 and 4.24 respectively. The maximum of CK's LAI was appeared in the August 4, while the $\mathrm{H} 2$ and $\mathrm{H} 3$ delayed 5 days than CK. The different between CK and $\mathrm{H} 1$ were not significant, but $\mathrm{H} 2$ and $\mathrm{H} 3$ LAI had reduced obviously. Above results indicated that water stress in tillering stage on soda saline-alkali soils, were not only affected the duration time of LAI, but impacted the growth situation of leaf.

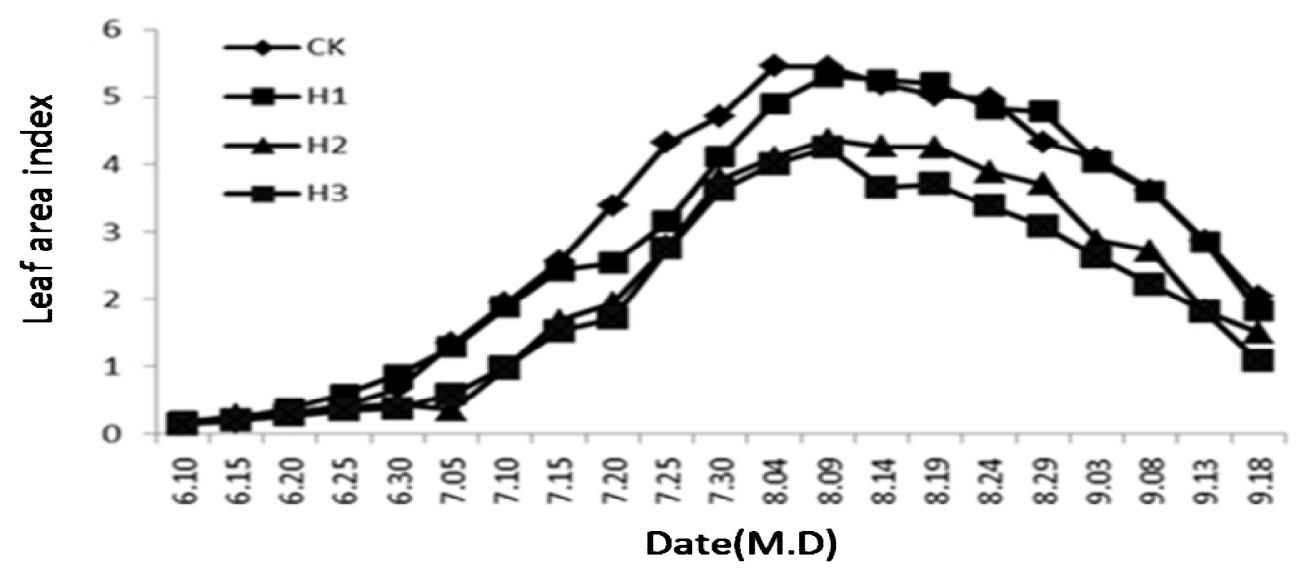

Fig.3 Effects of different soil water potential on leaf area index of rice 


\section{Dry matter content}

The dry matter of different part of rice under different soil water potential in soda saline-alkali soil showed a certain difference(Tab. 1). The plant growing of all the treats was consistent basically, dry matter had no significantly different after the end of treatment(June 24). After 15 days of rewatering, the total dry matter weight difference had become obviously, showed a trend of $\mathrm{H} 1>\mathrm{CK}>\mathrm{H} 2>\mathrm{H} 3$, the difference between $\mathrm{H} 1, \mathrm{CK}$ and $\mathrm{H} 2, \mathrm{H} 3$ had achieved the level of significance $(\mathrm{P}<0.05)$ and compared with $\mathrm{H} 2, \mathrm{H} 3, \mathrm{H} 1$ and $\mathrm{CK}$ were higher than $54.48 \%, 93.82 \%$ and $54.48 \%$, 93.82\% respectively. Total dry matter weight of all treatments showed a trend of $\mathrm{CK}>\mathrm{H} 1>\mathrm{H} 2>\mathrm{H} 3$ at heading stage(July 25) and dough stage(September 10), the difference had achieved significance level $(\mathrm{P}<0.05)$. Total dry matter weight of all treatments showed a trend of $\mathrm{H} 1>\mathrm{CK}>\mathrm{H} 2>\mathrm{H} 3$ at full heading stage(August 10) and Filling stage(August 25).

Further analysis table 1, we found that root dry matter weight showed wet condition is significantly higher than other treats, assumed $\mathrm{H} 1>\mathrm{CK}>\mathrm{H} 2>\mathrm{H} 3$. These indicated that in soda saline-alkali soils, kept the soil been in moist state was conducive to the growth of root and promoted to penetrate of roots of rice in tillering stage. With further decrease of soil water potential, under the effects of water stress and saline threat, rice root system had significantly affected and thereby affected the dry matter accumulation of the whole plant.

Table 1. Effects of different soil water potential on dry matter weight of rice

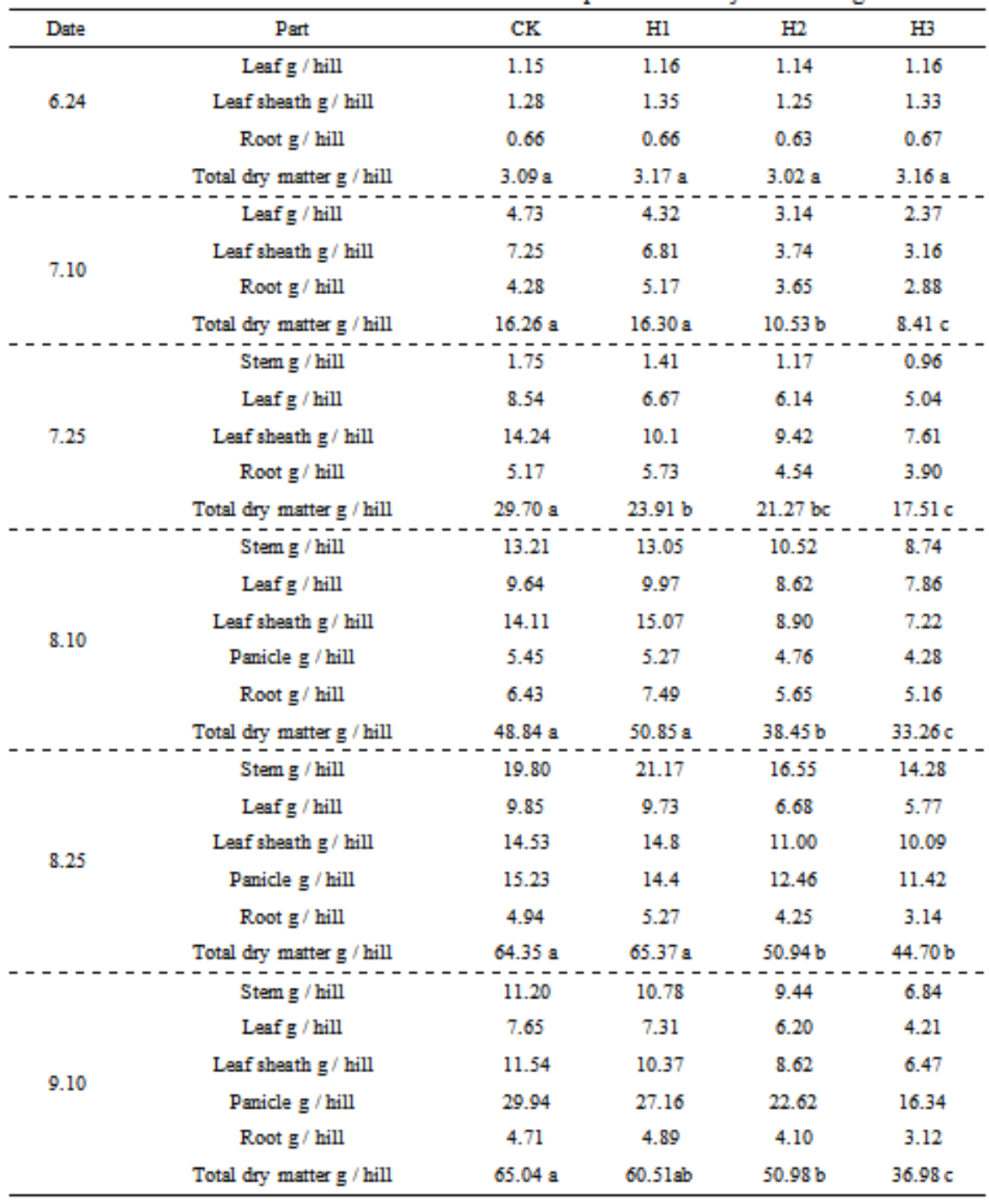

Values followed by different letters are significantly different at $\mathrm{P}<0.05$. 


\section{Yield traits and yield}

From the influence of different water treatment on rice yield (table 2), water stress at tillering stage had seriously restricted the normal growth of tillers of rice in soda saline-alkali soils. The panicle number of $\mathrm{CK}$ was more than other treats, although $\mathrm{CK}$ had some invalid tillers to death in later stage of tillering and had reached the significantly level $(\mathrm{P}<0.05)$. The grains per panicle and Seed setting percentage of CK were also higher than other treats, but there had no significant difference. We found that yield showed a trend of decreasing along with the water stress degree, characterized by $\mathrm{CK}>\mathrm{H} 1>\mathrm{H} 2>\mathrm{H} 3$, and had reached the significantly level $(\mathrm{P}<0.05) . \mathrm{H} 1, \mathrm{H} 2$ and $\mathrm{H} 3$ respectively $11.45 \%, 24.92 \%$ and $60.24 \%$ lower than the CK.

The above description indicted that the moisture deficiency conducted at tillering stage in soda saline-alkali soil, could inhibit the occurrence of rice tillers, and reduced the number of valid panicles per unit area, and was the main reason of significant reduction in the yield of rice.

Table 2. Effects of different soil water potential on yield and yield traits of rice

\begin{tabular}{ccccccc}
\hline Treats & Year & $\begin{array}{c}\text { Panicle number/ } \\
\text { per pot }\end{array}$ & $\begin{array}{c}\text { Grains per } \\
\text { panicle }\end{array}$ & $\begin{array}{c}\text { 1000-grain } \\
\text { weight/g }\end{array}$ & $\begin{array}{c}\text { Seed setting } \\
\text { percentage } / \%\end{array}$ & $\begin{array}{c}\text { Yield/ per } \\
\text { pot·g }\end{array}$ \\
\hline \multirow{2}{*}{ CK } & 2013 & 58.26 & 83.12 & 25.01 & 81.15 & 101.02 \\
& 2014 & 56.14 & 79.14 & 25.67 & 81.34 & 99.69 \\
& Average & $57.20 \mathrm{a}$ & $81.13 \mathrm{a}$ & $25.34 \mathrm{a}$ & $81.25 \mathrm{a}$ & $100.36 \mathrm{a}$ \\
$\mathrm{H} 1$ & 2013 & 50.04 & 83.07 & 25.42 & 80.19 & 91.84 \\
& 2014 & 53.58 & 79.13 & 25.98 & 81.99 & 89.16 \\
& Average & $51.81 \mathrm{~b}$ & $81.10 \mathrm{a}$ & $25.70 \mathrm{a}$ & $81.04 \mathrm{a}$ & $90.05 \mathrm{~b}$ \\
& 2013 & 49.17 & 79.03 & 25.11 & 79.24 & 80.03 \\
& 2014 & 48.85 & 77.97 & 25.33 & 77.32 & 80.65 \\
& Average & $49.01 \mathrm{~b}$ & $78.50 \mathrm{a}$ & $25.22 \mathrm{a}$ & $78.28 \mathrm{a}$ & $80.34 \mathrm{c}$ \\
& 2013 & 40.02 & 79.87 & 26.03 & 81.22 & 64.13 \\
& 2014 & 41.84 & 80.19 & 25.05 & 79.00 & 61.13 \\
& Average & $40.93 \mathrm{c}$ & $80.03 \mathrm{a}$ & $25.54 \mathrm{a}$ & $80.11 \mathrm{a}$ & $62.63 \mathrm{~d}$ \\
\hline
\end{tabular}

Data followed by common capital letters and lowercase letters within a column are not significantly different at the 0.01 and 0.05 probability levels, respectively.

\section{Conclusions}

Water treats of rice on soda saline-alkali soils, had greater effects on tiller number, and the valid tiller rate was at a lower level eventually. The expansion of the rice leaf area could been restricted by the changed of water potential at tillering stage, and with the aggravation of the water stress level, leaf area index had decreased. The maximum LAI of H2 (-15 Kpa) and H3(-30 Kpa) were appeared delayed 5 days than CK (continuously flooded). The plant growing of all the treats was consistent basically, dry matter had no significantly different after the end of treatment. We found that kept the soda saline-alkali soils been in moist state could conducive to the growth of root and promoted to penetrate of roots in tillering stage. Water stress had greater effect on tillers of $\mathrm{H} 2$ $(-15 \mathrm{Kpa})$ and $\mathrm{H} 3(-30 \mathrm{Kpa})$, the main reason was that the stress level was so larger by water stress associated saline stress intensity. So the number of tiller and plant growth were restrained, which result was lack of effective panicles per unit area and more to serious influenced the yield. In state of $\mathrm{H} 1(0 \mathrm{kPa})$, water stress was lighter than $\mathrm{H} 2$ and $\mathrm{H} 3$, but the yield was still lower than $\mathrm{CK}$ ultimately. Rice tillering stage of soda saline-alkali should maintain appropriate water layer, it can 
meet the required for normal growth and development of rice, and to guaranteed high yield.

\section{Acknowledgements}

This work was financially supported by the Jilin Province Young Investigator Foundation (20150520124JH), 13th Five Year of Science and technology research project of jilin province department of education (2016189), Jilin agricultural university, Dr. Start-up fund scientific research projects(2005005), and Modern agricultural industry technology system construction project of Jilin province.

\section{References}

[1] Shaoxi-wen, Majing-yong, Tongshu-yuan, et al.. Effect of different water disposal on growth and yield of rice in milking Stage, Journal of Irrigation and Drainage, 2006, 25 (3) : 41- 43.

[2] Chen guolin. The physiological and ecological effects of water saving irrigation on rice growth. Aeta Agriculture Universitatis Jiangxiensis,1996(2):160-166.

[3] Chen guolin, Wang zhaoqian. The effects of controlled moist condition irrigation on rice growth and water requirement. Journal of Zhejiang Agricultural University, 1997,23(2):123-127.

[4] Boonjung H, Fukai S. Effects of soil water deficit at different growth stages on rice growth and yield under upland conditions.1.Growth during drought. Field Crops Research,1996,48(1) : 37-45.

[5] Kato Y, Kamoshita A, Yamagishi J, et al.. Growth of rice (Oryza sativa L.) cultivars under upland conditions with different levels of water supply. Plant Production Science, 2007, 10(1) : 3-13.

[6] Peng S Z, Xu J Z, Huang Q, et al.. Experimental study on leaf water use efficiency of paddy rice under controlled irrigation. Transactions of the Chinese Society of Agricultural Engineering, 2006, 22(11) : 47-52.

[7] Wang Zhiqin, Yang Jianchang, Zhu Qingsen. Effect of soil moisture on Photosynthetic rate and matter translocation in rice plants. Chinese J Rice Sci, 1996, 10(4) : 235-240.

[8] Hu Jichao, Jiang Dong, Cao Weixing et al.. Effect of short-term drought on leaf water potential, photosynthesis and dry matter partitioning in paddy rice. CHINESE JOURNAL OF APPLIED ECOLOGY, 2004, 15(1): 63-67.

[9] Kumar R, Sarawgi A K, Ramos C, et al. Partitioning of dry matter during drought stress in rainfed lowland rice. Field Crops Research, 2006, 98(1) : 1-11.

[10] Cheng Jianping, Cao Cougui, Cai Ming li, et al.. Effects of different irrigation modes on biological characteristics and water use efficiency of paddy rice. CHINESE JOURNAL OF APPLIED ECOLOGY, 2006, 17(10) : 1859-1865.

[11] Lu J, Ookawa T, Hirasawa T. The effects of irrigation regimes on the water use, dry matter production and physiological responses of paddy rice. Plant and Soil, 2000, 223(1/2) : 209-218.

[12] Deng Huan,Cao Cou-Gui, Cheng Jian-Pin et al.. Impact of different irrigation methods on biological characteristics of rice. Chinese Journal of Eco-Agriculture, 2008,16(3):602-606.

[13] ShaoXi-wen, Zhang Rui-zhen, Qi Chun-yan, et al.. Effects of water stress on growth and yield of rice in jointing-booting stage. Journal of Jilin Agricultural University, 2004,26(3):237-241.

[14] Shao Xi-wen , Ruan Chang-chun, Zhao Lan-po, et al.. Effects of water stress on growth and yield of rice in tillering stage. Journal of Jilin Agricultural University, 2005,27(1): 6- 10.

[15] Kumar R, Sarawgi A K, Ramos C, et al. Partitioning of dry matter during drought stress in rainfed lowland rice. Field Crops Research, 2006, 98(1) : 1-11. 
[16] Cater G A, Cibula W G, Miller R L. Narrow-band reflectance imagery compared with thermal imagery for early detection of plant stress. Journal of Plant Physiology, 1996, 148(5) : 515-522.

[17] Belder P, Bouman B A M, Cabangon R, et al.. Effect of water-saving irrigation on rice yield and water use in typical lowland conditions in Asia. Agricultural Water Management, 2004, 65(3) : 193-210. 